\title{
The architectural culture of the Eurasian Mediterranean region: a testimony of satisfactory design for urban infrastructures (May 2014)
}

\author{
Susana M. Varela Alvaro and F. Javier Neila González
}

\begin{abstract}
The purpose of this paper is to expose the importance of observing cultural systems present in a territory as a reference for the design of urban infrastructures in the new cities and regions of rapid development. If we accept the idea that architecture is an instrument or cultural system developed by man to act as an intermediary to the environment, it is necessary to understand the elemental interaction between man and his environment to meet a satisfactory design.
\end{abstract}

To illustrate this purpose, we present the case of the Eurasian Mediterranean region, where the architectural culture acts as a cultural system of adaptation to the environment and it is formed by an ancient process of selection. From simple observation of architectural types, construction systems and environmental mechanisms treasured in mediterranean historical heritage we can extract crucial information about this elemental interaction.

Mediterranean architectural culture has environmental mechanisms responding to the needs of basics habitability, ethnics and passive conditioning. These mechanisms can be basis of an innovative design without compromising the diversity and lifestyles of human groups in the region. The main fundament of our investigation is the determination of the historical heritage of domestic architecture as holder of the formation process of these mechanisms.

The result allows us to affirm that the successful introduction of new urban infrastructures in an area need a reliable reference and it must be a cultural system that entailing in essence the environmental conditioning of human existence. The urban infrastructures must be sustainable, understood and accepted by the inhabitants. The last condition is more important when the urban infrastructures are implemented in areas that are developing rapidly or when there is no architectural culture.

Keywords - architecture, culture, design, domestic, dwelling, heritage, history, Mediterranean

Manuscript received May 14, 2014.

Susana M. Varela Alvaro is with the department of construction and technology, Technical University of Madrid, Spain (phone: 34 913866878; 34 645748825; e-mail: susa@ arquired.es).

F. Javier Neila Gonzalez is with the department of construction and technology, Technical University of Madrid, Spain (e-mail: Fjavier.neila@upm.es).

\section{INTRODUCTION}

$\mathrm{R}$ esearchers [1] - [2] from various disciplines consider that the possibilities and the limitations offered by the environment for the human adaptation are materialize in instruments or cultural adaptive systems that act as intermediaries between the human group and its environment. Tetsuro Watsuji [3] explains how man discovers himself as existing when becomes aware of its environmental conditioning, when it is reflected in instruments such as the home and clothing to protect against cold and heat. When we accept the environmental conditioning of human existence we can consider architecture as an instrument or an adaptation cultural system developed by man in their interaction with the environment.

By accepting the environmental conditioning of architecture we discover new opportunities to get crucial information on the interaction between man and its environment. The more we come to understand this elementary interaction is easier to make a satisfactory design of urban infrastructures for basic needs of human societies or groups. The environmental conditioning of architectural culture is appreciated through reflective observation the adaptive mechanisms deposited in domestic architecture and understanding their slow process to formation.

Our research experience reveals the importance of observing the cultural systems present in a territory as a reference for the successful design of new urban infrastructure in new vertical cities and regions of rapid development. To illustrate the importance of this consideration we present the mechanisms of environmental adaptation obtained as a result of our research in the Eurasian Mediterranean region.

\section{DOMESTIC ARCHITECTURAL CULTURE OF THE MEDITERRANEAN REGION}

Of the five Mediterranean ecosystems in the world, the Eurasian offers the best documented set of cultural systems developed by the process of humanization, with more abundant and diverse data. The Eurasian Mediterranean ecosystem is the cradle of Western civilization and millennia 


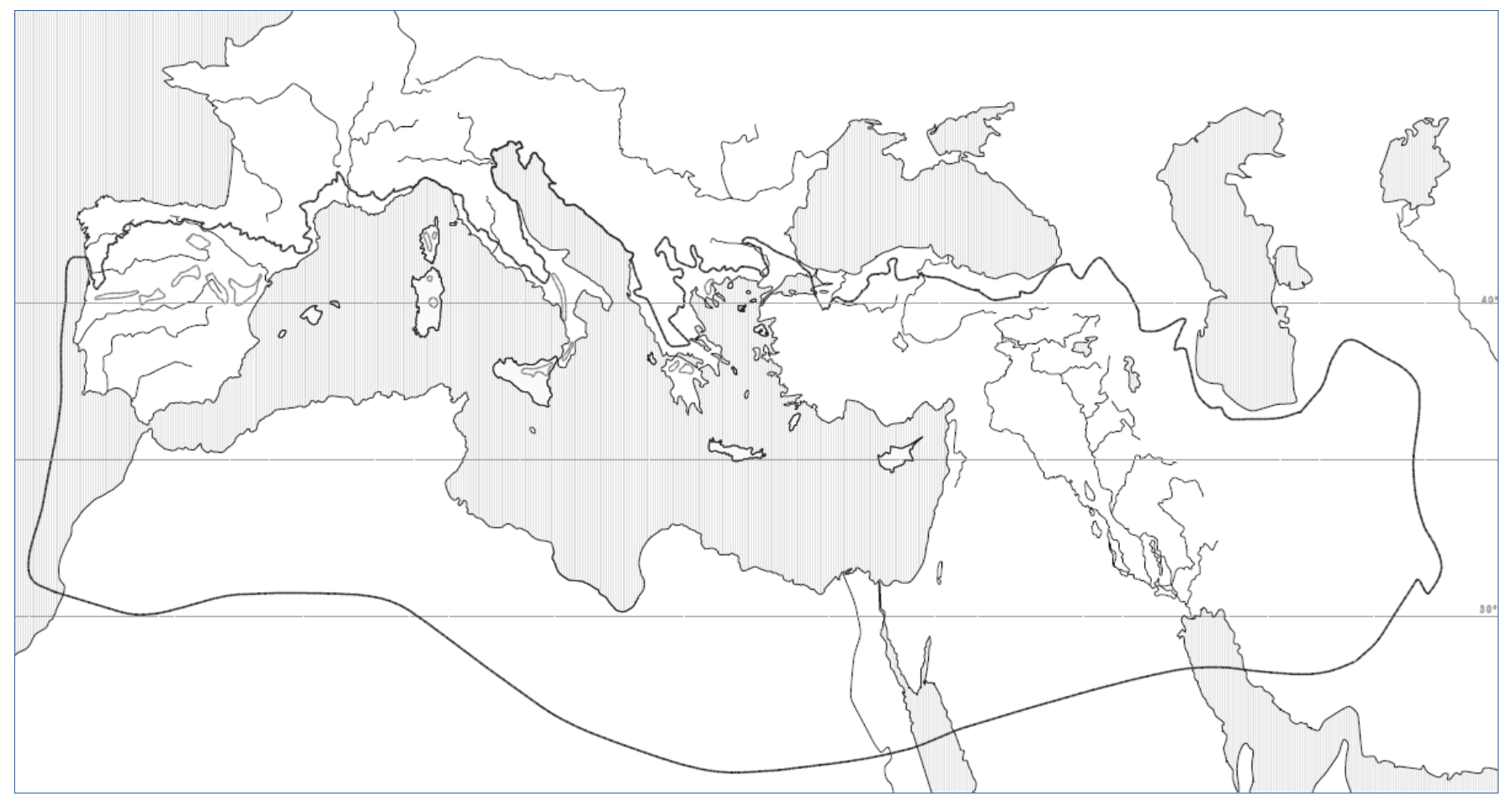

Fig. 1. Delimitation of the Eurasian Mediterranean territory based on the Worldwide Bioclimatic Classification System proposed by Salvador Rivas Martínez. Author.

ago that welcomes human activities. To mark their territory, stretching from the Iberian peninsula far surpassing the geographical basin of the Mediterranean Sea to overflowing the Iranian plateau by the East, has been taken as reference the geographic scope homogenized by the Mediterranean macrobioclimate. This macrobioclimate has been proposed by Salvador Rivas Martinez [4] in his bioclimatic classification of the Earth.

The architectural culture developed in this region is formed over millennia by an evolutionary process that remaining in spontaneous awareness of the Mediterranean peoples. In this evolutionary process which covers the period from the Neolithic revolution to the industrial revolution, we find new opportunities to study.

To find these opportunities, we have initiated a reflective observation of the mediterranean historic heritage of domestic architecture, where is manifested more clearly the environmental conditioning of architectural culture and the traceable its evolution process. The invariants of this architectural heritage show us a cultural system own of the region. This cultural system is endowed environmental mechanisms that verify the efficiency of the system and his correspondence with the lifestyles of the people in the region. These mechanisms can specialize by their origin in specific tactics and cultural strategies.

Environmental architectural tactics are devices, systems or habits that are integrated into a plan or strategy designed by the human groups in each area for the greatest welfare in built spaces. They are justified by minimize the spontaneous actions reducing the margin of error and help to arrange architectural resources. The tactics serve a specific purpose or need arising for reasons of basic habitability, ethnics or passive conditioning. Its concretion is based on an idea or principle and depends on the availability of resources and

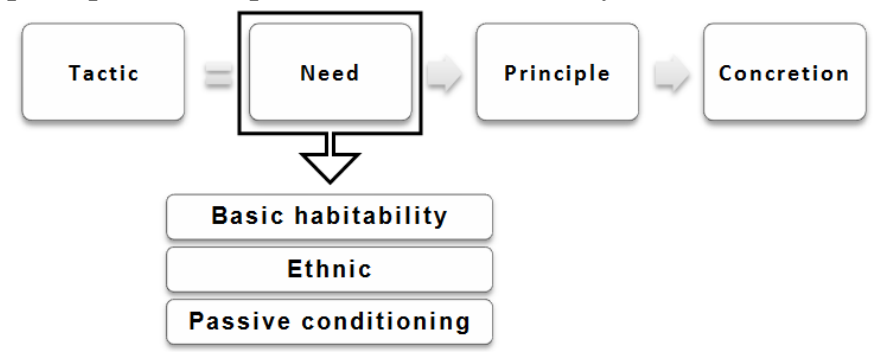

Fig. 2. Formation process of tactics. Author.

technical capacity of man. It is the group that dominates each territory who gives birth to the idea and materializes the tactic.

The mediterranean tactics are widespread throughout the region and are known by all people who live there. We organize them into three groups according to their specific objective: basic habitability, ethnic or passive conditioning.

Basic habitability tactics intend architectural spaces that meet the requirements for a healthy life, are the first to appear in the historical sequence and are materialized in the systems for protection against to climate factors, how to preserve and renew indoor environments and supply of water and light.

Ethnic tactics are typical of a people or human community with affinities in their way of life, in their social organization, in their family relationship, in the exchange relations or in the technical capacity to manage physical resources. These tactics facilitate the family relations, habits and lifestyle of every human group. 


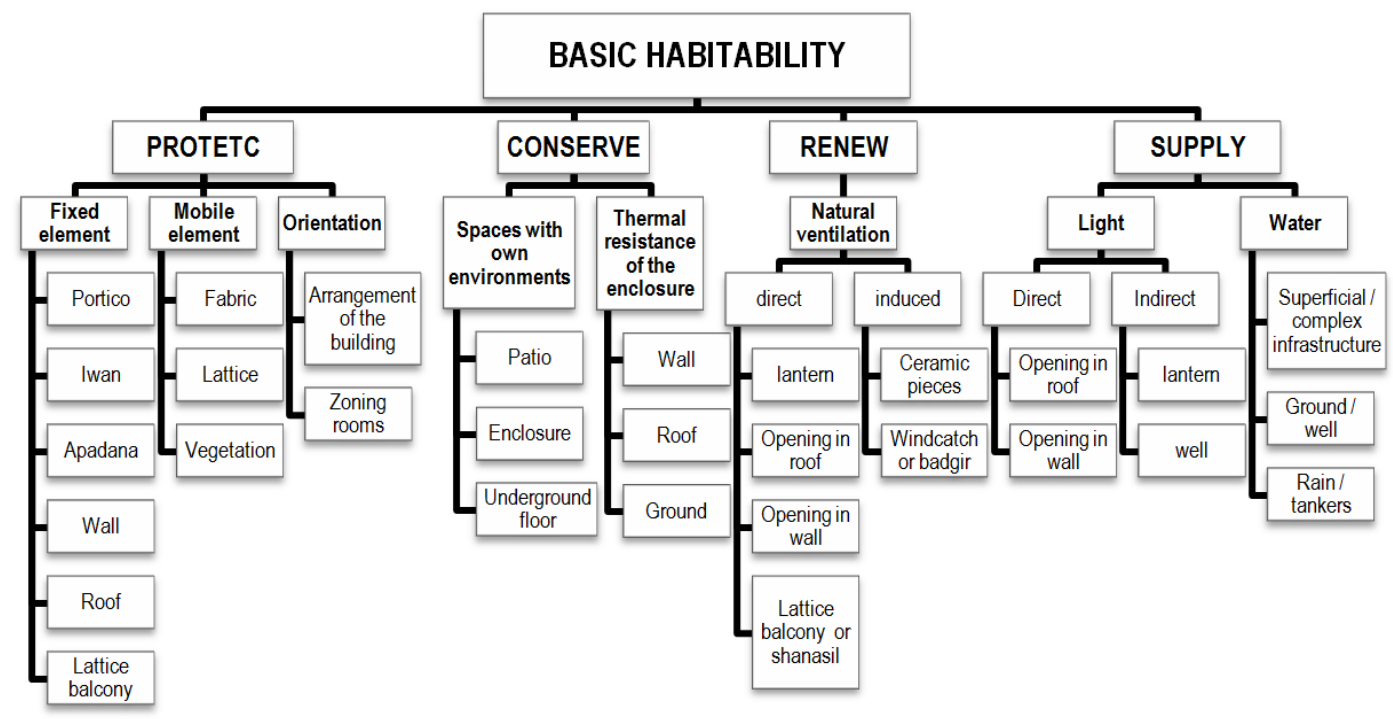

Fig. 2. Classification of basic habitability tactics observed in buildings of architectural heritage in the mediterranean region. Author.

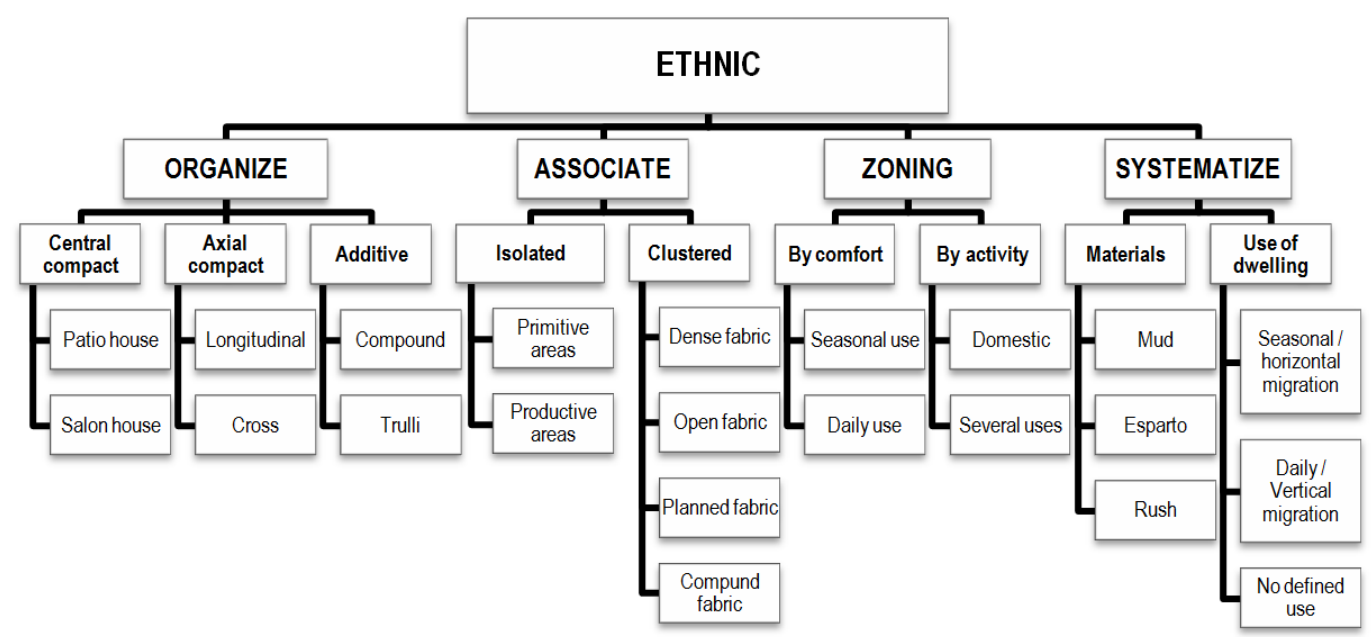

Fig. 3. Classification of ethnic tactics observed in buildings of architectural heritage in the mediterranean region. Author.

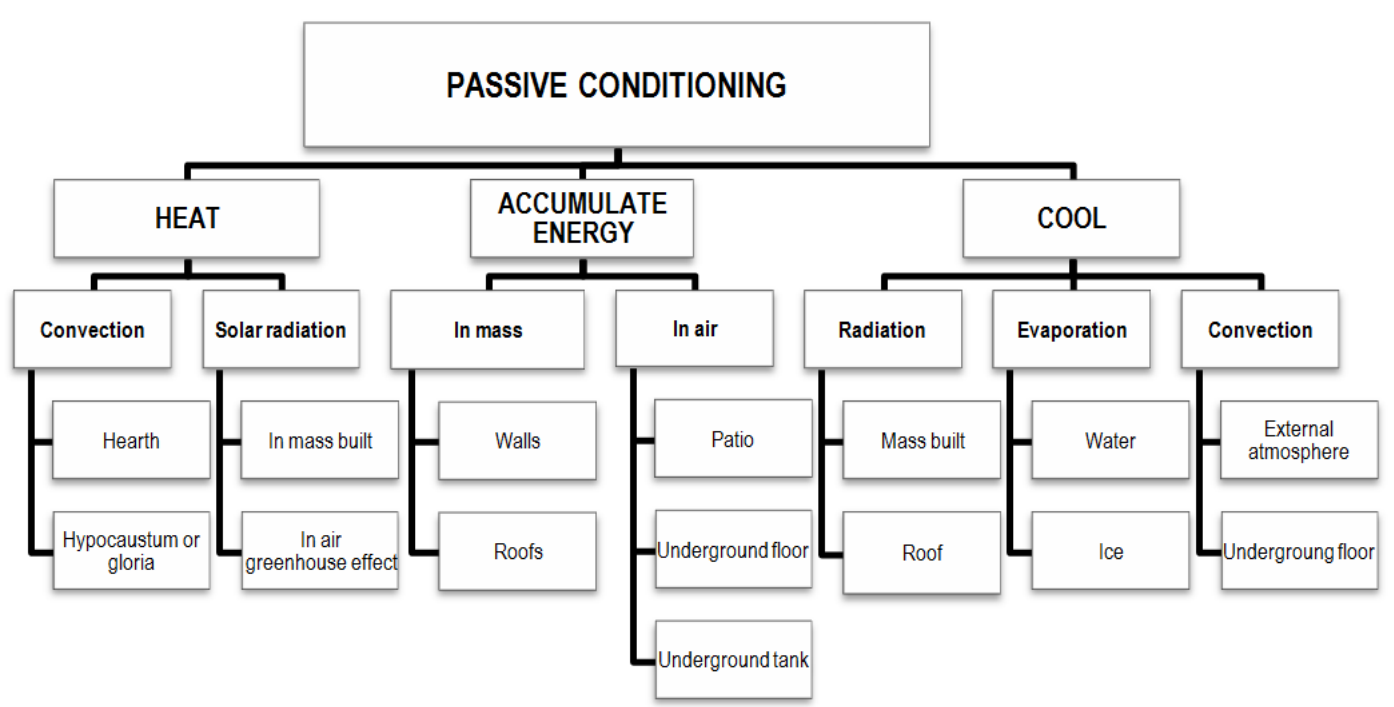

Fig. 4. Classification of passive conditioning tactics observed in buildings of architectural heritage in the mediterranean region. Author. 
They arise when the human groups have dwellings with basic habitability and begin to organize in complex societies. Dwellings are zoning, related forming urban fabric and used according to the comfort of the rooms. Appear new specialized types like the palace, the temple, the caravanserai, the castle, the fortress, the madrasa, the market.

The passive conditioning tactics are the last to show up in the historical sequence, they are more complex and aim to improve the basic habitability. They are based on physical principles of heat transfer and therefore require complex technical and scientific knowledge. Appear in more advanced civilizations that have developed systems of thought.

The arrangement of these tactics in the building is due to plans or strategies that depend on the technical expertise and cultural knowledge of the human group and how they operate in the different bioclimates. Both mechanisms, tactics and strategies, form the basis of a territorial cultural system which in its essence carries the environmental conditioning own of human existence.

The first architectural types that appear in the Eurasian Mediterranean region have an environmental essence and they form the basis of all subsequent architecture. These environmental mechanisms have been spreaded in the entire region by their inhabitants, reaching high levels of beauty and excellence. The periods of maximum diversity and cultural tolerance were during the empires of Assyrian, Roma and Persia. Currently these mechanisms remain in the built heritage of the region, with different intensity, forming the basis of an architectural culture endowed with a singular environmental conditioning.

We present the most singular mediterranean architectural tactics whose main objective is to protect the indoor environment of the building. These are materialized by the provision in the building of spaces endowed with own atmosphere that mediate into relationship of indoor air to the outside environment. The following table shows their historical anchor and how continues in the traditional architecture today and therefore in the spontaneous consciousness of the mediterranean peoples.

The reflexive observation from the historical heritage of domestic architecture in the mediterranean region shows that the process of formation of his architectural culture is not replaceable by a method based on models or predefined building types.

Much of the recently implemented urban infrastructures in the region show the loss of these environmental mechanisms. By its greatest impact, we highlight those mechanisms located in the envelope of buildings to protect, to conserve the indoor atmosphere and to mediate between indoor and outdoor environment.

The vertical architecture has emerged in the region as response to the economy of means or as a symbol of economic power. This architecture shows invariants opposite to the environmental mechanisms that characterize the mediterranean architectural culture. These invariants compromise the comfort of indoor and the traditional lifestyle.
The buildings have a simple and flat enveloping formed by smooth panels, unprotected and with holes evenly arranged on the facade, devoid of specialization. There are indoor spaces in direct relation with the outside, unprotected to the sun and the wind. The indoor welfare depends on the air conditioning systems operating with energies that are expensive by their little presence in the territory of the region.

This vertical architectural culture has its origin outside the mediterranean region. It began with the industrial revolution and established in temperate macrobioclimate. It is a cultural system own of a civilization that operates independently of its environment. The results of our research in the mediterranean region we suggest the following basics as essential:

1) The design of urban infrastructures for rapidly developing regions should be based on observation of cultural systems in the territory, or should be taken as a reference the systems developed by human groups with similar lifestyle living in similar bioclimates.

The architectural culture formed by the interaction between man and the environment, which resides in the spontaneous consciousness of the people, offers an ideal cultural system as a basis for new urban infrastructures. By contrast, a global architectural culture is a limitation to the possibilities offered by each territory and to the cultural response of human groups.

2) New towns should be popular, that is to say, must be accepted by the people because its transmission and preservation depends on it. New towns should incorporate infrastructures to make them recognizable, comprehensible and justifiable for the transmission to new generations. The urban infrastructures must get the closest reciprocity possible between the needs of the human group inhabiting the territory and the response provided by their design.

3) New infrastructures should be integrated in the cultural panorama of each area and, therefore, in its evolutionary process. The cultural system of each territory does not disappear and cannot be replaced by static global models. The presence of a static global system into a cultural context in progress cause marginal areas where chaos, poverty and dependence appear. 
TABLE I

BASIC HABITABILITY TACTICS. OBJECTIVE: CONSERVE. PRINCIPLE: USING SPACES WITH OWN ATMOSPHERE.

Tactic

Historical evidence

Current evidence

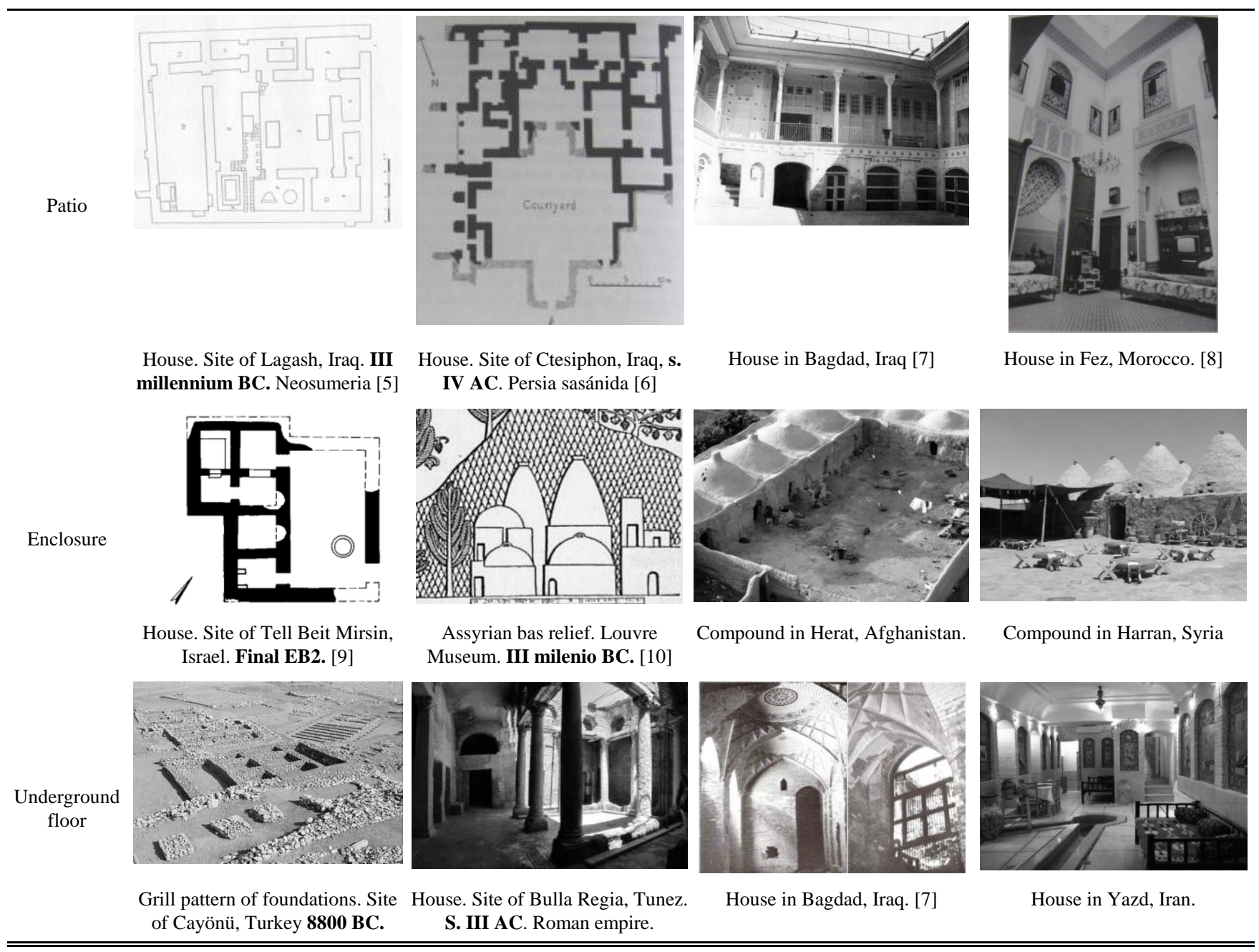

\section{CONCLUSIONS}

Moving towards a satisfactory design in new urban infrastructures requires decisive reflection about the environmental conditioning of human existence. The new urban infrastructures should ensure efficient response to the human adaptation to the environmental that meets goals of basic habitability, of ethnic and the passive conditioning. This requirement must be based on deep and thoughtful understanding of those cultural systems present in each territory because they are instruments of mediation between man and his environment and they have adaptation mechanisms formed by an evolutionary process that remain in the spontaneous consciousness of the people.

The architectural culture own of a territory is a cultural system endowed with environmental mechanisms that provide us crucial information about the interaction between man and the environment. We can observe these environmental mechanisms in the architectural heritage and take them as a reference for the design of new urban infrastructures in vertical cities and regions of rapid development.

This elemental information will allow that new urban infrastructures wear on their essence the environmental conditioning own of the human existence. The closer we get to understanding this environmental conditioning is easier for us to design infrastructures that meet the needs of human groups.

The human groups must understand and accept the new urban infrastructures to complete a cycle of efficient and sustainable living. It is important that we appreciate the urban infrastructures for its beauty, for its utility and for its degree of adaptation to the environment but we must not compromise traditional culture and avoid the imposition of new lifestyles.

Same time we must face a period of reflection that allows us to reach sure knowledge of the successes and failures that show vertical cities. The vertical architecture has prospered in some world regions generating powerful centers of attraction but opposing to the cultural system present in the spontaneous 
consciousness of the people. This situation has induced alarming situations of marginalization and poverty among the native groups. Therefore, it is necessary to incorporate the new urban infrastructures into the evolutionary process of the cultural systems own of each territory. And it is especially important implementing the environmental mechanisms of the architectural culture into these new urban infrastructures. The new urban infrastructures should ensure the sustainability and the equal opportunities for the different human groups and their cultural diversity.

\section{REFERENCES}

[1] C. L. Redman, Los orígenes de la civilización: desde los primeros agricultores hasta la sociedad urbana en el Próximo Oriente. Barcelona, Spain: Crítica, 1990

Redman argues that man's interaction with the environment is the reason for the changes that led to the advent of civilization.

[2] E. Guidoni, Arquitectura primitiva. Madrid, Spain: Aguilar-Asuri, cop. 1989

[3] T. Watsuji, Antropología del paisaje: climas, culturas y religiones. Salamanca, Spain: Sígueme, 2006

[4] S. Rivas Martínez \& S. Rivas Saenz, 1996-2009. Worldwide Bioclimatic Classification System. Phytosociological Research Center, Spain. Available: http://www.globalbioclimatics.org

[5] A. Parrot, Tello, vingt campagnes de fouilles (1877-1933). Paris: Editions Albin Michel, 1948.

[6] A survey of Persian art, from prehistoric times to the present. v.2, Sasanian period Architecture, pottery, textiles, metalwork, jewelry, seals, coinage. $2^{\mathrm{a}}$ impresion. Original edition published in London 19389. Gran Bretaña: Editor Arthur Upham Pope, 1967.

[7] J. Warren y I. Fethi, Traditional houses in Bagdad. Horsham England: s.n., 1982.

[8] J. Revault, L. Golvin y A. Amahan. Palais et demeures de Fés II. Epoque Alawite (XVIIeme et XVIIIeme siécles). Paris: CNRS, 1989

[9] Eliezer D. Oren, "Palaces and Patrician Houses in the Middle and Late Bronze Ages", The architecture of ancient Israel from the prehistoric to the Persian periods, pp. 105-120. Jerusalem 1992

[10] S. Meca, Earthen domes and habitats. Villages of Northern Syria. Edizioni ETS. Pisa, 2009

Susana María Varela Alvaro. Madrid, Spain. Architect, School of Architecture, Technical University of Madrid, July 1992. Research proficiency Ph.D., Program in Construction and Architectural Technology, Technical University of Madrid, September 2001. Thesis in progress. Advisor: Francisco Javier Neila González.

She was guest lecturer in Ph.D. Program in Construction and Architectural Technology, School of Architecture, Technical University of Madrid, November 2013. Lecturer in Urbanism, School of Architecture, University Camilo José Cela, Madrid, 2008-2009. Architect in several firms and public companies in Madrid. Published paper by ECSEE 2013, United Kindong, ISSN 2188-1146.

Francisco Javier Neila Gonzalez. Madrid, Spain. Architect, School of Architecture, Technical University of Madrid, 1976. PhD in architecture since 1984. University professor since 2007.

$\mathrm{He}$ is director of Masters in Environment and Bioclimatic Architecture, since its inception in 2001. Principal investigator of the research group ABIO, Bioclimatic Architecture in a Sustainable Environment. He has directed 29 competitive research projects. Author of 25 articles in indexed journals. Author of over 90 books on sustainability, habitability and energy. More than 100 papers at Congress. He has 12 patents on new systems and sustainable materials. He had received 14 awards of investigation and architecture. He is currently coordinator of several undergraduate and graduate courses in the School of Architecture of Technical University of Madrid. 